\title{
Performing the Swahili Hamziyyah and the Pyeongtaek Nongak: A Comparative Analysis of Community Dance and Rituals.
}

\author{
Prof. Tom Olali ${ }^{1}$ \\ University of Nairobi, and Visiting Associate Professor in the Division of African Studies, \\ College of International and Area Studies, Hankuk University of Foreign Studies, Republic of Korea
}

\begin{abstract}
My first and most enduring lessons on per formative events came from the maulidi festival of the Lamu archipelago, Kenya. Bands of Swahili passed year after year before my eyes during this festival to mark the anniversary of the birthday of the Prophet Muhammad. In 2014, I came to Korea and in November of the same year, I managed to attend the Pyeongtaek nongak(also known as pungmul), a widely-transmitted traditional performance format blending music, dance and theatre. This paper was initiated to compare the performance of the hamziyyah during the maulidi festival in the Lamu archipelago, Kenya and the nongak, a traditional Korean music performed by farmers in the Republic of Korea. I give particular attention to the role they play during the festivals and as a medium which is employed to reinforce values of the Swahili people of the Lamu archipelago and that of Korean people respectively. This paper illustrates how the hamziyyah and the nongak are performed during the Lamu maulidi festival and at Gyeongbokgung palace in Seoul and their subsequent transmission. The performance includes the musical ensemble, the dances, the performers and the latent functions that the hamziyyah and the nongak provide.
\end{abstract}

Key words: Hamziyyah, maulidi, nongak,

\section{INTRODUCTION}

\subsection{Research Design and Methodology}

To discuss this paper, I will try to apply some of the questions posed by Finnegan, and apply them to the performance of both the hamziyyah and nongak. These are: who, when, where, what and how? Who performs it, and who listens to it? What are the occasions, places, and times of performances? What is the poetry like, and what are its subjects and contents? How is it performed and listened to? (1992: 53-57). The performance of poetry entails a performer, a setting, an audience, and a performance style. The term itself implies focus on the person performing, but in fact, nearly all-critical discussions mainly concern the audience and its responses.

Adapting Finnegan's parameters in performance, I will analyze and explore the nature and structural components of the hamziyyah performance and the nongak performed by residents from the region of Gyeonggi province in the Republic of Korea.

\subsection{Methods and procedures}

I have been studying performative events for the last twenty years. At the University of Nairobi at the Centre of Korean Studies, I came across nongak performance and was very much interested to see occurrence of any similarities or differences with the performance of the hamziyah during the maulidi festival.

I came toKorea in the fall of 2014 as a Visiting Professor. On 29th November 2014 after the 4th Humanities Korea International Conference, I went to Gyeongbokgung Palace to see the nongak performance. At this juncture, I would like to present the procedures that I employed to determine the hamziyyah text and nongak from Pyeongtaek that this study is premised. Pyeongtaek is a city in Gyeonggi province, South Korea and is located in the Southwestern part of the province. Pyeongtaek has had open fields called sosabeol, and traditionally its people have farmed. This was a crucial background for developing the Pyeongtaek nongak. The performance is rich in music ensemble compared to the other nongak.

\footnotetext{
${ }^{1}$ Corresponding Author: tom.olali@gmail.com
} 
For the hamziyyah, the methodology I followed consisted of collecting the hamziyyah texts in the field, and observing and participating in the hamziyyah performance itself. In addition, the research for both the hamziyyah and nongak were carried out using self-report, a term ordinarily used to refer to any data or information provided by the subject (Wulff 1995). During both the maulidi festival in the Lamu archipelago and the nongak, I met men from Pate Island while in the Republic of Korea, I met informants from Pyeongtaek. My informants had a considerable knowledge of the hamziyyah as was my informants particularly from Pyeongtaek. In Seoul, I arranged interviews with the performers from Pyeongtaek with the help of a translator. They gave me hand-written information on pieces of paper. They used Han-gul, the Korean phonetic alphabet while for the hamziyyah, the informants used both Roman and Arabic scripts.

Part of this research was library based, the central one being the University of Nairobi library which I visited in the first and second month of 2015 and the Hankuk University of Foreign Studies Library, both at Global and Seoul campuses. Oral interviews were carried out in the Lamu archipelago as another means of gathering data. The interviews were conducted in Lamu, Pate, Siyu, and Faza, (as the main centres of the research). These areas are reputed to be home to northern dialect speakers and reciters of the hamziyyah, particularly Pate. The language of the interviews was Swahili, Korean and English. The language of the hamziyyah during the maulidi festival was Swahili while that of nongak was Korean. For hamziyah, a small amount of Arabic is used in performance but is always translated immediately into Swahili, except for some standard opening and closing formulas: bismi allahi al-rahmani al-rahim (in the name of God the Most Merciful the Most Compassionate), which the Muslims typically utter when starting any task. For nongak, one woman read a prayer loudly praying their hopes to god. Nongak has its roots in trying to appease the gods in order to have an abundant harvest.

My participation in both the maulidi festival and the nongak was important to me since I learnt much by observation. For example, the different components of the hamziyyah performance and its delivery to the audience by the performers relied so much on observation. This was also the case with nongak. For example the social and physical setting, the musical instruments that accompanied the dances, the body movements and audience participation, and the ages of the participants. The climax of my research in the Lamu archipelago was the recording of the hamziyyah. I also recorded the hamziyyah without the inclusion of the musical instruments like vigoma (small drums) and matwari (tambourines) so as to get the words clearly. I arranged different sessions with Maalim Dini who was and still remains the chief performer. Recording was done in Mombasa with Maalim Dini alone. My own collection, which has been accumulated over the fieldwork period, consists of the hamziyyah as recited by the " Experts of Pate" and the one recited by Maalim Dini in Mombasa without the assistance of the other performers.

\section{RESUlTS AND DISCUSSION}

The hamziyyah performance during the maulidi festival is usually organized and is coordinated by an executive committee, the Riyadha mosque committee. Islamic students in Muslim Academy take part in assisting with the preparations. Individuals also help organize it. In the case of nongak, it is organized by the Cultural Heritage Administration of South Korea. At this point, I return to the subject of participation in religious events. Religious events can be divided into two main categories: ritual and ceremonial. Ritual events have a transformative purpose and are associated with transition from one social status to another. For example, birth, circumcision, marriage, deaths are ritual events.

\subsection{Setting of the hamziyyah and nongak Performance}

The setting is one of the most influential components of any performative event. Coulthard states, "sometimes (setting) is one of the defining criteria of an event such that it occurs at a specific time or specific place" (1985:44).

\subsubsection{Temporal Setting}

In Lamu archipelago, every locality has its own favourite poem or dance, which is performed during the maulidi festival. In Pate for example, the hamziyyah is the most popular. Evening is the preferable time for hamziyyah performance. There is no prohibition against its performance at any time of the day, however, there are those who believe that reciting the hamziyyah on Thursday night bring baraka (blessings) because God's grace is more fully realized on that particular day. The nongakgroupperforms their favourite songs and later joins the street parade through Gwanghwamun as it heads toward the Heungnyemun gate at Gyeongbokgung palace. Similarly for the hamziyyah performance, the performers participate in a parade called zefe and performance with other groups in street parade along the narrow streets of Lamu as they head to the burial site of al-Habib Swaleh Jamal Layl,a local saint. The parade begins from his house, a well preserved semi permanent house and located opposite Riyadha mosque and college. 


\section{American Research Journal of Humanities and Social Sciences, Volume 1, Issue1, Feb-2015}

ISSN 2378-7031

\subsubsection{Spatial Setting}

The hamziyyah performance is not confined to any specific place. It can be held anywhere in the vicinity of the ceremonial event except in the mosque. In these specific locations, the hamziyyah performance is held in conjunction with communal ceremonial events. Apart from the 29th November when the Pyeongtaek group performs in Seoul, they also perform in other events in Gyeonggi province. Given its associations with jovial community events, it is perceived as the embodiment of joy and ecstatic excitement among the Korean people. Today, private circles frequently perform nongak, and it is also included in the school curriculum.

The hamziyyahperformanceis greatly affected by cultural considerations. Men are expected to sit or stand beside other men, while women sit or stand beside other women. Children below the age of puberty are free to move and sit wherever they wish. Older and prominent men are expected to be in the middle and in the forefront, while other less senior men stand on the peripheries of the rectangular socio space away from the centre stage.This is not the case with nongak performance. Audience composition is not restricted in any way.

\subsection{Keying into performance and music ensemble}

Okpewho refers to the keying into performance as pre-performance organization and chores and mentions the procuring of materials for masks and drums and individual's initiation (1990:10). Except the Islamic utterance of bismi allahi al-rahmani al-rahim, no ritual is required to accompany the start or the end of the hamziyyah performance. Muslims are urged to voice this utterance at the beginning of any occasion or before taking any action. There are no purification rites to protect, say for example, the rectangular space. For the nongak, a prayer is uttered to the god.

In the hamziyyah performance, small drums or big drums are not used. Graham says Swahili people refer to the traditional music as 'ngoma', a Swahili word meaning both music and dance and which is now used generically to describe the music, the dance and the occasion at which they are performed (1992:158). Marjorie holds similar view when she points out that the word 'ngoma' in Kiswahili means both 'drum' and 'dance' and also the combination of drumming, dancing, and singing that so often occurs (1986:72). The rectangular social space is cleared of running children, and positions are set for the performers, audience-participants, tambourine drummers, children, women and elders. The nongak generally consists of the delicate beats of the kkwaenggwari (small handheld gong), the heavy feeling of the jing (large gong), the perky beats of janggu (hour glass-shaped drum), the pounding tunes from the buk and sogo (small hand drum) all combine to raise emotions to a climax. Besides, a taepyeongso (conical double-reed oboe) and a nabal (brass trumpet) are used in some bands.

\subsection{The hamziyyah and nongak Performers}

Harding remarks, "There is a two-layered presentation of the self as performer. Firstly as 'body' (that is the physical presence) and secondly either as a 'character' (a fictional persona) or as an extension of one's own persona (nonfictional)" (2002:3). During the performance of the hamziyyah, the presentation is that of physical presence. They do not present any fictional persona.

In the hamziyyah, the recitation and the whole act of performing it by "experts of Pate" is the performance.Succession to the powerful positions, which the hamziyyah chief performer may hold, is not hereditary.This means, therefore, that powerful dynasties of poets cannot establish themselves in the Lamu archipelago. However, I established that poetic skills revolved around particular families. Maalim Dini's family is among the famous Swahili families, the Nabhany, whose members are still performing their grandfather's poetry. The performers in a nongak are called jaebi or chibae. Other members of the band include the flags and dancers, called japsaek, which include hunters, Buddhist monks, brides and so forth. When a band marches, the flags lead the members in front and the musicians and the dancers follow in line. Exuberant sounds, dizzily swinging heads and colourful parades characterize it.

To prevail as a competent expert (fundi), an aspiring performer must learn the hamziyyah by heart and enrol as an apprentice with one of the "Experts of Pate" in a kinara (a special place for teaching poetry).It is a small tower, a turret, a pillar or column, a candelabrum. It has the shape of a minaret (mnara). The word kinara merely means a small minaret. Olali observes that training of poets is also a common practice, found in places as far apart as medieval Ireland and Scotland, Polynesia and central Africa, and shows the seriousness with which the acquisition of poetic skill and knowledge is regarded (2008: 85; 2012).

Nongak performance is now included in the school curriculum. There are nongak training centres. 


\section{The Hamziyyah And NongaK Performance}

The hamziyyah is not performed using ngoma.To usher in the beginning of the performance, all the performers utter the essential Islamic phrase: bismi allahi al-rahmani al-rahim. They begin the performance by beating the tambourine gently. The young men who play the tambourinesbeat them simultaneously with special techniques to produce different melodies. The tambourine is beaten aloud to proclaim the start of the hamziyyah. The leading reciter starts with the first stanza of the hamziyyah. The performers chant aloud with the audience periodically joining in the refrain. The chief performers chant the verses in high-pitched tones punctuated by sounds of the matwari (tambourines).

In the hamziyyah, the headword is stressed and repeated twice, thrice or even sometimes four times. The matwari are beaten continuously for a long time in an unchanged pattern and hardly stopped or beaten lightly because of refrain or the chief performer singing the line of the moment. This means the chief performer has to sing loudly to come above the sound of the matwarito be audible enough to the audience. The chief performer sometimes sings in Arabic followed by Swahili, and sometimes, Swahili alone. Each of the three performers has an equal share of the lines they are to chant during the performance. Each performer only recites a couplet or two and let the other performer takes over and vice-versa. After an Arabic line, a Swahili line is recited, and then the performer leads into the refrain in Arabic.

In the hamziyyah performance, the start of the next line is left to any of the chief performers. One interesting characteristic of the hamziyyah performance is that the lines do not follow line after line as they appear in the hamziyyah. It may prove difficult for a person who depends on the text to follow closely as they recite. However, each of the chief performers takes 2-3 lines pertaining to a particular theme and they do not mix the themes. In other words, they try as much as possible to follow the thematic pattern of the hamziyyah. Every time each completes a couplet or two, the performers and the male audience wishing to join in repeat the refrain, and the young performers would beat the tambourines viciously. The women at this time only look at the performers and do not join in the refrain. So important is the intensity factor in the hamziyyah performance that the trio has to recite the lines in turns to keep the tempo. Nketia made similar observation when writing about the intensity factor in African music. He states: “...in some societies, provision for generating or sustaining the required levels is made in the distribution of performance roles” (1988:56).

The three chief performers move from right to left carrying their walking sticks, and moving closer to the audience. Their movement is in rhythm, coinciding with the beating of the matwari at a moderate pace. The chief reciter stand in front of his performers, the other performers standing in parallel rows holding hands and periodically kneeling, going sideways and jumping up in ecstasy. They also turn around on their own axis (at 360 degrees) simultaneously. They turn around about three times before moving forward again. The young men beat the matwari louder, with the added impetus, they become fully ecstatic.

In order to work at the next line, the performer has to repeat a key word or phrase. Sometimes he retains the same syntax as changing only a word or two. When a certain word or phrase which he had previously uttered for some reason remained in his mind, it may appear several lines later in another semantic and syntactic context. Because of the length of the hamziyyah, there is latitude over the verbal structuring of the piece during the performance to the extent that 'improvisation' or 'original composition' within established conventions become more applicable terms than the re-rendering or a variant of a known piece. In addition, during the performance, the public space where they perform becomes the stage where the performers display their skills, a sign of the reversal of things, a space where the powerless take over.

In nongak, there are three major dance styles related to the gut. One is the ogugut, also called ssitkimgut, performed for spiritual cleansing. Another is chaesugut, performed to invoke good fortune and peace of the family; while the other is sonanggut, a gut performance performed by the community to invoke its well-being. Nongak performers wear a variety of colourful costumes. Aflower version of the Buddhist kkokkal. Advanced performers sometimes wear sangmo, which are hats with ribbon attached to them that the players can spin and flip in intricate patterns by moving their heads. When nongak is focused simply within a single village, the band is commonly comprised of village residents; when it is undertaken collaboratively by a number of villages, locals with reputations for exceptional proficiency are selected to form a percussion band. The nongak dance is made up of 12 parts including "small drum dance" by young men, "human pyramid" by children, traditional "flat drum dance" by a group of people, "hourglass drum dance" by both male and female dancers, "fan dance" originating from ancient "sorcerer's dance" by multiple people holding big floral fans, imitative "crane dance" and finally, the most impressive "sangmo dance" by male dancers. Drumming is the central element of nongak. Minyo (folksongs) and chants are included and 


\section{American Research Journal of Humanities and Social Sciences, Volume 1, Issue1, Feb-2015}

ISSN 2378-7031

audience members enthusiastically sing and dance along. Most minyo are set to drum beats in one of a few jangdan (rhythmic patterns). Following the drummers are dancers, who often play the sogo(a small drum without enough resonance to contribute to the soundscape significantly) and tend to have more elaborate-even acrobaticchoreography, particularly if the sogo-wielding dancers also manipulate the sangmo ribbon-hats.

\section{INTENTIONS AND FUNCTIONS}

In his article, "Four functions of folklore," Bascom enumerates the functions of folklore as follows; it manifests everyday life in a given culture; it justifies the values of the culture through the explanation of myths, rites, institutions; it has an educational role, especially in illiterate societies; and it maintains the conformity of accepted behaviour (1954:67).

For the hamziyyah, the event itself denotes its social or religious intention. In ritual rites including events of birth, death, or the rite of initiation (circumcision, marriage) the audience's intention is to secure the blessing of the Prophet for the initiatee and for themselves. The hamziyyah itself is also viewed as a hirizi (talisman) and an amulet amongst the Swahili people of the Lamu archipelago. When you memorize the hamziyyah or have the hand-written copy of it, then you enjoy its talismanic property.

By joining in the refrain during the hamziyyah performance, the audience's intention is to invoke the help and blessings of the Prophet and remember him through the hamziyyah. This action is believed to generate and fulfil that intention (blessings of the Prophet). The hamziyyah performance is the means through which participants attempt to attain their goals. It is being described as hajji toto (mini pilgrimage) by Lamuans who get satisfaction by going to the tombs of local saints like al-Habib Swaleh. In other words, as Kruger points out, "these enactments were felt to have the power of rites of passage or liminal performances" and that "they marked a fundamental and collectively acknowledged breach in the life of a community..." (1999:23). During the recitation of the hamziyyah during maulidi festival, the occasion is understood in terms of birth renewal, kind of new birth, and to the Moslems, they go back to the time of the Prophet Muhammad and that they are in actual sense, re-enacting the time Prophet Muhammad lived in this world.

In addition, the hamziyyah performance fulfils latent functions in the community. The poetry itself is loaded with litanies and the hagiography of Prophet Muhammad. It also contains the creeds of the Islamic religion and many supplications and solicitations for guidance. Through 'informal education', community members learn of their numerous religious facets, learning what is sacred and profane. The 'informal education' that took place 'in context' is fulfilled unintentionally by listening to the hamziyyah poetry.

It is a source of enlightenment and edification in response to which contemporary generations draw inspiration to rise up to the challenges of their own age in the same way as their ancestors are believed to have risen up to the challenges of their own more difficult times, in their heroic age. The hamziyyah gives a legendary account based on a chronology of historical facts dealing with the wars of the Prophet after the hijra. Another latent function that the hamziyyah performance fulfils is the enhancement of group social cohesion within the community. Since performative events are occasions of communal gathering, they provide opportunities for community members to meet and visit each other, thus, strengthening social bonds. In a community where kinship is the fundamental social ties, such events provide another means for social interaction. Sometimes these gatherings facilitate the establishment of new social ties among non-relatives.

On its part, nongak inspires the farmers to labour energetically and to settle their solitude and pain of their isolated existences to sublimate them into pleasure. It is not only used to alleviate farmers' fatigue and pain, but is also used as ritual for the god, or in a battle field to expel the enemy. In the end, nongak is by nature a progressive act combining group desire, and an art of revival and survival to overcome pain with enthusiasm. Nongak accompanies various villages events held to fulfill a range of functions: village rituals to appease guardian spirits; door-to-door rites to ward off evil spirits and summon in good fortune at the start of a year; percussion performances to raise communal funds; farming rites wishing for or celebrating an abundant harvest; and rituals to welcome fishing boats as they return from the sea. Nongak helps to enhance solidarity and cooperation in the community members. It continues to be at the core socio-cultural identities in modern Korea. For nongak, there is intimate relationship between the agricultural circle and shamanistic music. Gut, or shaman rites and nongak or farmer's percussion music, both combine ritualistic and entertainment features. The Korean people perceive nongak as gut, overflowing with things to see and enjoy. 


\section{CONCLUSION}

At the end of this paper, I would like to draw attention to a number of observations and points that are important for the general understanding of the hamziyyah and nongak performance.

Although the performance of the hamziyyah and its transmission in the Lamu archipelago during the maulidi festival flourish now, the question which has to be asked is whether there is any future for it. There are certainly three factors, which may affect the perpetuation of the hamziyyah performance in the Lamu archipelago. There is the material reward the reciters should enjoy, the recognition of their skills. The question of economics may very well not have occurred to the performance of the hamziyyah-as yet, although they are already justifiably concerned about the use to which recordings of their performances are put. Generally speaking however, they have been performing the hamziyyah all these years because they belong to a poetic family, and also because they obviously gain real satisfaction and enjoyment from doing so. For nongak, although having undergone surface changes, it has sustained musical, dancing, and dramatic components that can be considered quintessentially Korean. During the performance of the hamziyyah and nongak, questions presented by Finnegan are exhibited in the audience. For hamziyyah, the temporal and spatial setting of the performances is strictly governed by the Islamic codes and community norms unlike the nongak.

\section{ACKNOWLEDGMENT}

This paper was made possible through the support of the Division of African Studies, College of International and Area Studies, Hankuk University of Foreign Studies, Republic of Korea.

\section{AUTHOR'S BIOGRAPHY}

Prof. Tom Olali is a visiting scholar in the Division of African Studies, College of International and Area Studies at Hankuk University of Foreign Studies, South Korea and teaches Swahili at the University of Nairobi. He holds a $\mathrm{PhD}$ in African Studies from the School of Oriental and African Studies (SOAS), University of London and MA in Swahili Studies from the University of Nairobi. His field of interest is in Swahili Islamic Civilization. He has published An English Rendition of a Classical Swahili Poetry, The Performance of a Swahili Poem during the Maulidi Festival, Performing Arts in Lamu, Mafamba (fiction), Watu wa Gehenna (fiction), Mwongozo wa Utengano, among other Publications. His articles have been published widely in various international journals.

\section{REFERENCES}

[1] Bascom, W (1954) "Four Functions of Folklore" Journal of American Folklore.

[2] Coulthard, M (1985)An Introduction to Discourse Analysis. London: Longmans.

[3] Finnegan, R (1992) Oral Traditions and the Verbal Arts. London: Routledge.

[4] Graham, R (1992) The World of Africa Music, Vol.II. London: Pluto Press.

[5] Harding, F(ed) (2002) The Performance Arts in Africa. London: Routledge.

[6] Kruger, L (1999) The Drama of South Africa: Plays, Pageants and Publics since 1900. London: Routledge.

[7] Lambert, M et al (2011) Pyeongtaek Nongak. Southport: Betascript Publishing

[8] Marjorie, A (1986) Anyone can dance: a Survey and analysis of Swahili ngoma, past and

[9] present. PhD dissertation, University of California

[10] Nketia, J (1988) “The Intensity Factor in African Music” in Stone, R(ed)

[11] Performance in Contemporary African Arts. The Journal of Folklore Research. African Studies. Indiana University Press.

[12] Okpewho, I (1990) The Oral Performancein Africa. Ibadan: Spectrum Books Ltd.

[13] Olali, T (2008) Performance of a Swahili Poem during the LamuMaulidi Festival. South Bend: Sahel Publishing Press

[14] Olali, T (2012) Perfoming Arts in Lamu. Berlin: Lambert Academic Publishing

[15] Wulff, D (1995) "Psychological Approaches" in Whaling, F(ed) Theory and

[16] Method in Religious Studies. Berlin: Mouton de Gruyter. 